\title{
Unburned hydrocarbon formation in a natural gas engine under sea wave load conditions
}

\author{
Sadi Tavakoli ${ }^{1,2} \cdot$ Michael Vincent Jensen $^{2} \cdot$ Eilif Pedersen $^{1} \cdot$ Jesper Schramm ${ }^{2}$
}

Received: 19 December 2019 / Accepted: 15 April 2020 / Published online: 4 June 2020

(c) The Author(s) 2020

\begin{abstract}
Although natural gas is documented as a low-emission fuel compared to the other traditional fossil fuels in internal combustion engines, recent research indicates large amounts of methane emission released by lean burn gas engines and highlights the importance of this emission on global warming. This paper aims at illustrating the main sources of unburned fuel in internal combustion engines with an emphasis on spark ignited natural gas engines. In addition, two unburned hydrocarbon modeling patterns, empirical and thermodynamic, are proposed. Moreover, a verified engine model including all components with an implemented dynamic load based on harmonic sea waves has been set up and coupled to the unburned hydrocarbon formation models. Results show that load variation may contribute to further methane slip and this increment rises sharply when the load amplitude enlarges. The maximum amount of methane slip occurs at reduced loads when the time lag of the control system of the turbocharger causes additional fresh air to flow towards the combustion chamber and brings the flame into the quenching area. As well, inspecting unburned hydrocarbon emission in diverse air-fuel ratios but with the same wave frequency and amplitude uncovers the sensitivity of lean burn gas engines to the dynamic load.
\end{abstract}

Keywords Natural gas engine $\cdot$ Sea wave $\cdot$ Unburned hydrocarbon $\cdot$ Emission modeling

\section{Introduction}

The importance of toxic effects and global warming potential of emission compounds from industrial activities in our daily life have been investigated for decades, and environmental legislation is going to be more strict for these applications. International standards such as the Euro norms and the IMO regulations [1,2] have imposed more strict levels for emission compounds, especially from engines; for instance, Tier III [3] only allows almost one-fifth of $\mathrm{NO}_{\mathrm{X}}$ emissions compared to Tier I for marine Diesel engines. The Paris agreement also compelled the authorities to get engaged into the challenge of global warming to keep the overall warming below $2{ }^{\circ} \mathrm{C}$ [4]. Acquiring these new emission targets for internal combustion engines would only be applicable if at least one of the following items be taken into account:

Sadi Tavakoli

sadi.tavakoli@ntntu.no

1 Department of Marine Technology, Norwegian University of Science and Technology (NTNU), Trondheim, Norway

2 Department of Mechanical Engineering, Technical University of Denmark (DTU), Copenhagen, Denmark
- Aftertreatment system.

- Design modification.

- Alternative clean fuels.

Using aftertreatment systems in gasoline and Diesel engines to comply with the emission legislation is a necessity, but these systems not only add costs to the engine, but also need regular maintenance. Design modification has always been an upgrading process to improve engine performance and emission. An example of a work in this fields is the work done by Karthickeyan [5] which showed that piston bowl design boosts swirl and squishes stream lines and the result is a better mixing process of air and fuel. Furthermore, Sadiq and Iyer [6] tried to optimize a small-volume high-speed engine with various fuels and crown geometries, and they concluded that engine behaviour will be enhanced by having a higher turbulent air mixture inside the chamber. Compression ratio optimization, intake and exhaust port modification, fuel system development, exhaust gas recirculation, ignition timing correctness, and accurate control system implementation are other examples of design modifications. Since the customers usually prefer less-complicated lessexpensive engines, substituting the conventional fuel with 
an alternative pure fuel to reach the emission target would be a fair solution. Among all, natural gas in lean burn SI engines or dual fuel engines with a pilot of diesel fuel has got more popular, since application of this fuel contributes to a drastic reduction in emission compounds without additional expenditure for clients. Rosli Semin [7] reported up to $85 \% \mathrm{NO}_{x}$ reduction and $30 \% \mathrm{CO}_{2}$ and $95 \% \mathrm{CO}$ reduction in natural gas engines. Therefore, these engines allow manufacturers to a high extent to meet emission legislations without any fundamental modification on the engine or even using aftertreatment systems [8].

Considering the main purpose of this paper, we mostly describe spark ignition natural gas engine performance and emissions. In contrast to the low aforementioned emission compounds, high amount of methane slip is still a challenge for lean burn gas engines. Although in the initial IMO strategy report, published on April 2018 [9], only considerations to address volatile organic compounds are recommended. It seems that in an early future, a very restricted requirement will be imposed on unburned hydrocarbons, since the global warming potential (GWP) value for methane is 28 times higher than for carbon dioxide on 100 years prospective, based on report by The Intergovernmental Panel on Climate Change (IPCC) [10]. Even a research by Brynolf et al. [11] emphasized that using natural gas in marine applications will not improve the greenhouse gas effect compared to heavy fuel oil because of the methane slip.

In this paper, we present the main sources of methane slip in engines and pay a special attention to natural gas engines. In addition, to recognize the importance of each source on the total unburned hydrocarbon formation during transient conditions which has never been studied before, a developed thermodynamic engine cycle model with an incorporated emission model is considered together with an empirical emission model, and both are coupled to the output of an engine simulation from a commercial software. Since the engine is designed for marine applications, time-based harmonic loads are imposed on the engine.

\section{Unburned hydrocarbon formation}

\subsection{Sources of unburned hydrocarbon}

Unburned hydrocarbons (UHC) are typically an output of incomplete combustion due to unfavorable engine design, low fuel quality or failure in the control system. UHC exists in both SI and CI engines, while in the latter one, the $\mathrm{HC}$ compounds contain higher molecular weight due to the higher boiling point of the diesel fuel spray [12]. In SI engines, seven classifications can be introduced for sources of UHC:
1. Crevice volume.

2. Wall layer quenching.

3. Pockets of partially reacted mixture.

4. Misfiring.

5. Oil films.

6. Deposits.

7. Valve overlap.

The significance of these sources is highly depended on the engine application whether it is stationary or non-stationary and type of fuel whether it is liquid or gas.

\subsubsection{Crevice volume}

The regions in the combustion chamber located somewhere between the piston and the liner, the intake and exhaust valve seat gaps, and the injector groove in direct injection engines are all crevice volumes, which account for almost $5 \%$ of the trapped and non-reacted mixture in the initial combustion [13]. Wentworth [14] illustrated that his modified piston and top ring minimized the crevice volume, and as a consequence, exhaust hydrocarbons was halved in a wide range of loads and speeds. A restriction of reducing the crevice volume, especially between the piston and the liner, is the existence of an oil layer for lubrication, since the temperature of the oil should not exceed $170{ }^{\circ} \mathrm{C}$. Therefore, having a quenched flame in such area is crucial [15]. Increasing the top land crevice to pass two plate wall quenching as recommended by Huang et al. [16] reduced UHC up to $50 \%$, although a $1-3 \%$ fuel consumption increment was also observed.

\subsubsection{Wall layer quenching}

Liner and piston surfaces are the coldest areas during the combustion phase due to the existence of a water cooling system around the liner and an oil cooling system (not for all engines) on the bottom of the piston. These cooled surfaces transfer energy from the hot gas mixture and create a cold thermal layer close to these regions. This phenomenon ceases the flame propagating and is called flame quenching in the layer adjacent to the wall. Previously, it was assumed that a high percentage of the UHC emission origins from wall quenching, but after developing new technical methods, [17] researchers discovered the impact of post-flame combustion on oxidizing the quenched mixture.

\subsubsection{Pockets of partially reacted mixture}

Depending on how turbulence influences on the flame, the combustion will be enhanced or quenched. Swirl originating from the intake port and tumble from the piston bowl shape both promote mixing of air and fuel in the combustion 
chamber. In case the turbulence increases significantly, the flame front breaks up and leaves pockets of unburned mixture. These pockets are in fact source of unburned hydrocarbon and can exceptionally have a determining function under warming up [18], especially if the target is transferring enthalpy release toward the exhaust port to heat up a catalyst faster in slow combustion [19].

\subsubsection{Misfiring}

Regardless of reason for misfiring, whether it is due to high dilution with air and exhaust gas, or a fault in the spark plug, or even malfunctioning of the control system [15], the consequences of such an event is that a considerable mass of unburned hydrocarbon is released into the exhaust system. In case of an explosion in the exhaust manifold, turbine, or catalytic converter damages are impending, and otherwise, UHC compounds will be released into the atmosphere. In standard SI gasoline engines, only a defective spark plug and control system may contribute to the misfiring, while in a lean-burn gas engine, high dilution may also result in partial misfiring and cycle-to-cycle variations.

\subsubsection{Oil films}

Due to solubility of fuel in the oil, a portion of the fuel near the cylinder wall will be absorbed by the lubrication oil film. The quantity of fuel absorbed or desorbed is a parameter sensitive to the oil and fuel specification, oil and fuel temperature, oil film thickness, and time [20]. To confirm this point, a work considering a mass diffusion equation and Henry's constant has been done by Schramm and Sorenson [21]. They revealed that the desorbed hydrocarbons from oil film are extremely dependent on the thickness of the film. This is, however, for a film thickness of up to 2 microns and there would be no shift in thicker films.

\subsubsection{Deposits}

When oil and fuel burns on the surfaces of the combustion chamber, a sheet of deposits forms on the major part of the surfaces including piston, liner, valve seats, and even crevices [22]. Kalghatgi [23] studied the influence of deposits on the production of $\mathrm{NO}_{x}$, since he believed that deposits reduce the heat loss to the coolant fluid and, as a consequence, increase the thermal $\mathrm{NO}_{x}$, while the increase in surface and gas temperature results in less unburned hydrocarbon. Meanwhile, deposits will partly fill the crevices and the UHC created due to crevice volumes reduces. In contrast, these deposits absorb part of the unburned fuel like an oil film. He concluded that there is no solid conclusion about the impact of the combustion chamber deposits. Other studies, however, showed that between $0.5 \%$ [13] and $1 \%$ [24] of the injected fuel will be sent out of the combustion chamber unburned due to deposits on the surfaces. Stepien [25] listed the main effects of engine deposit formation and reasoned that the porous nature of deposits in the combustion chamber and the capability of absorbing fuel contributes to a higher amount of UHC emission.

\subsubsection{Valve overlap}

The valve overlap period is the period where both the intake and exhaust valves are open, and the boost pressure drives the fresh air-fuel mixture directly from the intake port to the exhaust port without taking part in the combustion. This phenomenon arises only in premixed combustion engines where a mixture of air and fuel enters through the intake valves. The wasted mixture is a function of the overlap duration and boost pressure, and could be the source of approximately 5\% of UHC [26]. An optimum timing for the inlet and outlet valve openings and their designs relies on several factors such as engine application, engine respiration, speed, EGR, and so on. For instance, camshafts are usually designed based on a trade-off among engine lower speed with least EGR and engine higher speed with the best scavenging and required EGR. Otherwise, a very short overlap contributes to a higher rate of EGR in low load, and this dilution increases the risk of partial burn misfiring [19].

\subsection{Difference between the influence of gas and liquid fuel in formation of UHC in SI engines}

To explain the importance of state of matter of combustible on UHC product, Landsberg et al. [27] injected liquid and evaporated gasoline fuel inside the combustion chamber and observed that the liquid fuel flow produces between three and seven times greater quantity of UHC in association with the same fuel as vapor, and this rises if this fuel is to be injected directly in to the combustion chamber.

Robison and Brehob [28] used a liquid fuel vaporization carburetor to render a stronger homogeneous mixture of air and fuel. The result shows less UHC emission during warmup when liquid fuels cannot be vaporized suitably in the port and the cylinder, and regional rich mixtures occur in the combustion chamber. Similar works $[29,30]$ prove that part of the fuel injected to the intake port will generate wall wetting in the cold start. Tilagone and Venturi [31] changed a gasoline engine of vehicle application to a natural gas engine to evaluate the performance and emission of the engine, and they demonstrated that natural gas contributes to a remarkable decline in emission compound, meaning $50 \%$ less UHC compared to a gasoline engine. The main reason for this drop is the limited oil film adsorption-desorption phenomenon. Kato et al. [32] showed that less UHCs released from the same performance gas engine than the gasoline engine is due 
to less wall fuel flow in the intake system. Besides, sources of methane slip in the work of Zwart [15] are overlap, misfire, and crevices, and matching with other sources of UHC in typical SI engines, and deposit and oil film are omitted as sources of UHC in SI natural gas engines, if we classify wall quenching as a misfire.

Concerning the literature review, the main causes of UHC in natural gas engines can be interpreted into crevice volume, gas exchange, and flame quenching unburned hydrocarbon. Considering the essence of utilizing natural gas in a very lean burn mixtures, these sources still will produce a substantial volume of UHC in the lean-burn natural gas engines.

\section{Unburned hydrocarbon modeling}

To determine the disparity of formation of UHC in steadystate and dynamic conditions, a nine-cylinder natural gas engine has been modeled thermodynamically in details with the commercial software, GT Power, and its output is implemented into an empirical UHC modeling within this software. Moreover, a separate thermodynamic engine model has been developed to distinguish the individual sources of UHC formation. The schematic of the procedure of the modeling is shown in Fig. 1. Detailed equations are presented in Sect. 3.1 and 3.2. For simplicity, the empirical UHC model is named Type $\mathrm{E}$, and the thermodynamic UHC model is named Type $\mathrm{T}$.

\subsection{Empirical modeling of UHC formation: Type E}

The Quench layer is normally the layer at the end of the flame, i.e., near the walls, while the flame itself is normal, parallel or at an angle to the wall. The flame quenching process occurs based on the second rule of thumb criteria by William [33]: The rate of liberation of heat by a chemical reaction inside the flame segment must approximately balance the rate of heat loss from the segment by thermal conduction. Relating the heat release to the heat loss can be done by a non-dimensional Peclet number, which is relatively constant in a wide range of geometrical configurations. For two plate quenching, the Peclet number is determined by:

$P e_{2}=\frac{\rho S_{\mathrm{L}} c_{\mathrm{P}, \mathrm{f}} d_{\mathrm{q} 2}}{k_{\mathrm{f}}}$

where $\rho, S_{\mathrm{L}}, c_{\mathrm{P}, \mathrm{f}}, d_{\mathrm{q} 2}$, and $k_{\mathrm{f}}$ are the density, laminar flame speed, specific heat at constant pressure, two-plate quench distance, and thermal conductivity, respectively. Lavoie [34] developed an empirical correlation for two-plate quench

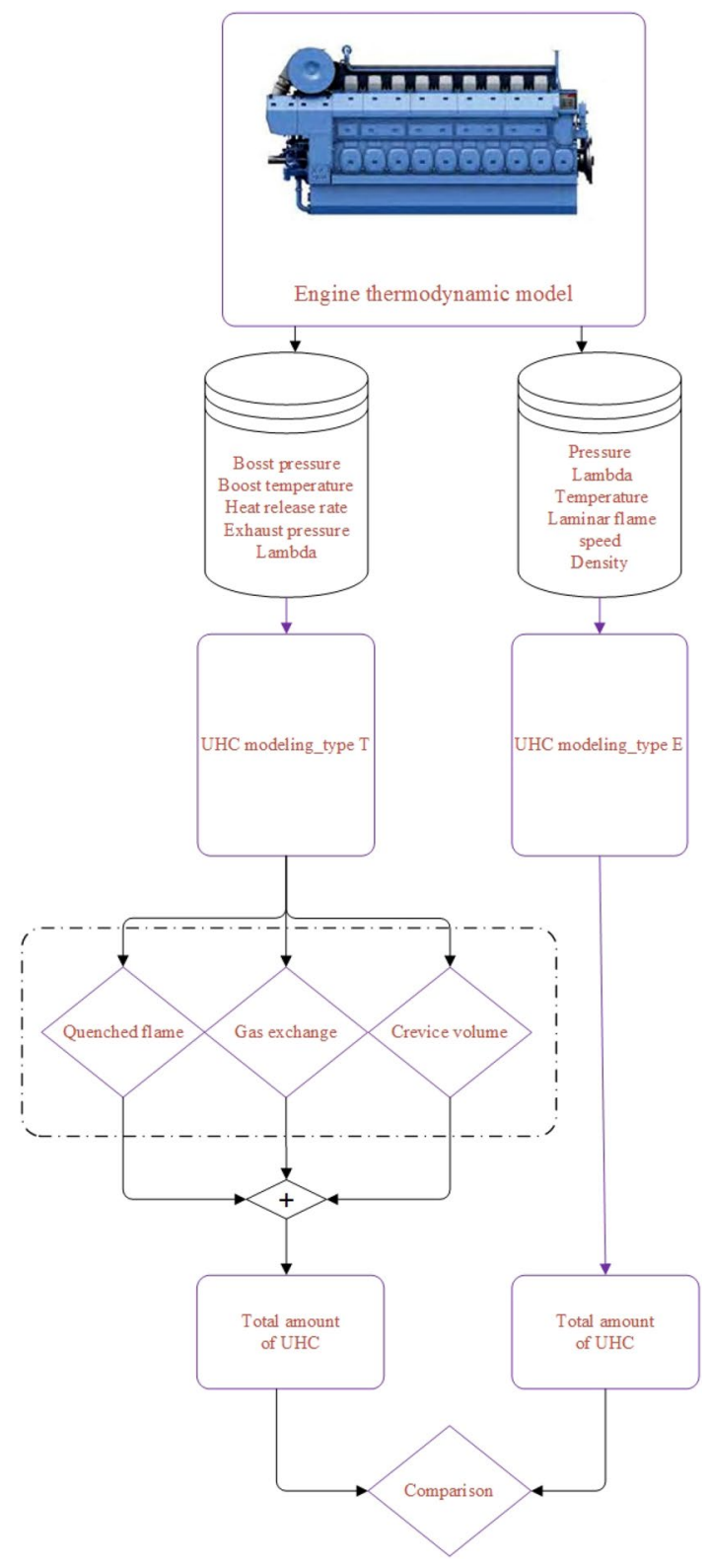

Fig. 1 Emission modeling flowchart

distance which is well fitted for a range of pressure between 3 and 40 bar with:

$P e_{2}=\frac{9.5}{\phi}\left(\frac{P}{3}\right)^{0.26 \min \left(1,1 / \phi^{2}\right)}$,

where $P$ is pressure and $\phi$ is equivalence ratio. Calculating $P e_{2}$ which is Peclet number for two-wall quenching, and laminar flame speed, Eq. (3) gives us the two wall quench distance in Eq. (1):

$(1-f) S_{\mathrm{L}}=A(\phi) P^{n} e^{-E(\phi) / 2 R T_{\mathrm{f}}}$, 
where $f$ is dilution effect, $A$ is pre-exponential factor, and $E$ is activation energy.

Lavoie then recommended that two- and single-plate quenching distance have the constant proportion in Eq. (4) as shown in Fig. 2 [34]:

$\frac{\mathrm{d} q_{1}}{\mathrm{~d} q_{2}}=\frac{P e_{1, \mathrm{u}}}{P e_{2, \mathrm{u}}}=0.20$.

To calculate the amount of fuel captured in the quench layer, it is necessary to integrate the quench layer content; however, Lavoie recommended an experimentally expression for this amount, as:

$\left(\int_{0}^{\infty} \rho z \mathrm{~d} y\right)_{\mathrm{f}}=\frac{\rho_{\mathrm{u}} \mathrm{d} q_{2}}{22}$,

where $y$ is perpendicular distance from the wall and the mass fraction of unburned gas is $z=\frac{\mathrm{HC}}{\mathrm{HC}_{0}}$, where $\mathrm{HC}_{0}$ is initial concentration of hydrocarbons in the unburned mixture. The quench layer UHC will undergo post-oxidation according to the new defined mechanisms $[34,35]$ :

$\frac{\mathrm{d}(\mathrm{HC})}{\mathrm{d} t}=-6.7 \times 10^{15} e^{\frac{-37230}{R T}} f_{\mathrm{HC}} f_{\mathrm{O}_{2}}\left(\frac{P}{R T}\right)^{2}$.

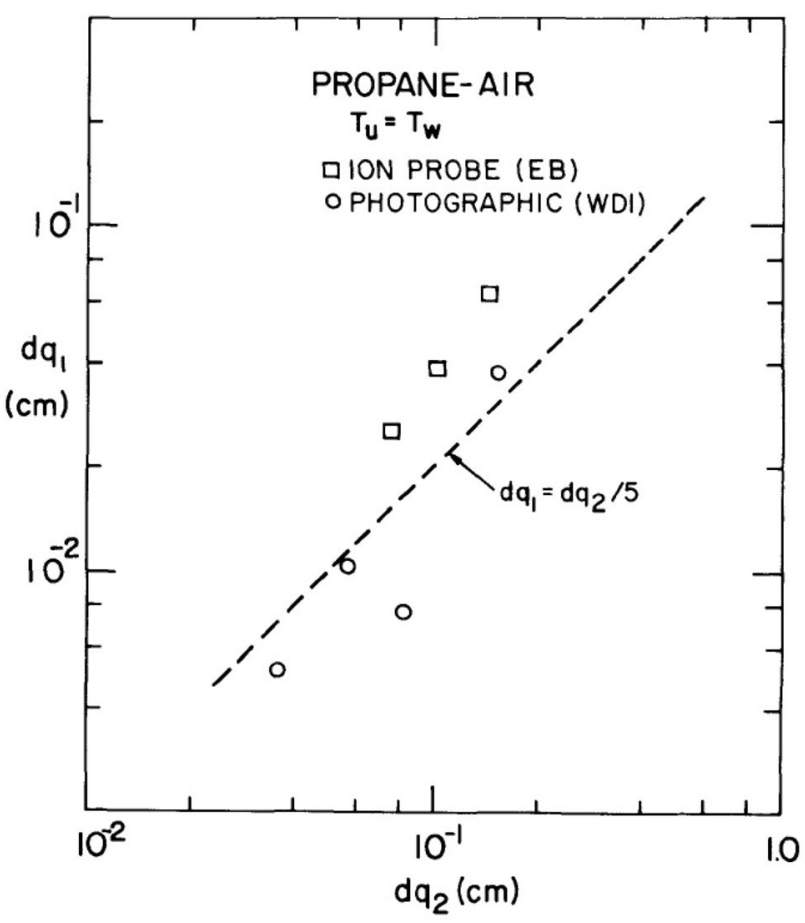

Fig. 2 Single-wall quench versus two-plate wall quench $\left(\mathrm{d}_{{ }_{1}}\right.$ vs $\mathrm{d} q$ 2) [34]
If the pressure, temperature, and fuel species fraction stay high enough, a dominant contribution of unburned fuel burns in the post-oxidation process from the end of the main combustion till the end of the cycle.

In this section, two additional sources of the UHC including crevice volume and blown by mixture during the gas-exchange process have been taken into account, as well. Mass of mixture trapped in the crevice volume is calculable by volume and density, and depending on the maximum pressure crank angle, the gas will participate partially in the main combustion and the post-oxidation process. Moreover, the calculation of the gas-exchange UHC source does not need any extra modeling than the quasi-steady modeling.

\subsection{Thermodynamic modeling of UHC formation: Type T}

The developed thermodynamic engine model is a three-zone full engine cycle model developed with the aim of obtaining information on the source distribution for the unburned hydrocarbon emissions which is not possible in the applied commercial engine simulation software. The model, TECMU, is described in more details in [36]. The model estimates the contribution to the total unburned hydrocarbon emissions from three sources: crevices, wall quenching, and short-circuiting due to valve overlap. To do so, this model is coupled with the output from the commercial engine simulation software. The engine operating condition and calculated outputs are given as input to this model. This ensures that the two models (Type $\mathrm{E}$ and Type $\mathrm{T}$ ) simulate the same engine operating state. The contributions to the total unburned hydrocarbon emissions from different sources are then obtained as an output from the Type-T model.

The procedure of a Type-T simulation is: the estimation of the contribution from the crevices to the unburned hydrocarbon emissions is based on a mass balance for the cylinder content of fuel from the crevice volume. From the mass balance equation, the instantaneous in-cylinder mass fraction of fuel from the crevices $y_{\mathrm{f}, \mathrm{cy}}^{\mathrm{cr}}$ is calculated. The contribution to the total unburned hydrocarbon emissions from the crevices $m_{\mathrm{f}, \text { out }}^{\mathrm{cr}}$ is then determined by integrating the product of $y_{\mathrm{f}, \mathrm{cy}}^{\mathrm{cr}}$ and the total mass flow rate out of the engine, $\dot{m}_{\text {out }}$, over the exhaust phase of the engine cycle:

$m_{\mathrm{f}, \text { out }}^{\mathrm{cr}}=\int_{\mathrm{ex}} \dot{m}_{\mathrm{out}} y_{\mathrm{f}, \mathrm{cy}}^{\mathrm{cr}}$.

Estimation of the contribution from short-circuiting to the engine out emissions of unburned hydrocarbons is performed similarly and simultaneously. The cylinder content of fuel from the intake manifold is calculated based on a mass balance which enables the instantaneous in-cylinder mass fraction of fuel from the intake manifold, $y_{\mathrm{f}, \mathrm{cy}}^{\mathrm{sc}}$, to be 
determined. The contribution from short-circuiting to the unburned hydrocarbon emissions is obtained by integrating the product of $y_{\mathrm{f}, \mathrm{cy}}^{\mathrm{cr}}$ and $\dot{m}_{\text {out }}$ :

$m_{\mathrm{f}, \text { out }}^{\mathrm{sc}}=\int_{\mathrm{ex}} \dot{m}_{\mathrm{out}} y_{\mathrm{f}, \mathrm{cy}}^{\mathrm{sc}}$.

A separate mass balance equation for the total fuel mass in the cylinder is used to determine the instantaneous in-cylinder fuel mass fraction $y_{\mathrm{f}, \mathrm{cy}}$. The mass of total hydrocarbon emissions $m_{\mathrm{f}, \text { out }}$ is then calculated as:

$m_{\mathrm{f}, \text { out }}=\int_{\mathrm{ex}} \dot{m}_{\text {out }} y_{\mathrm{f}, \mathrm{cy}}$.

The relative contributions from crevices, short-circuiting, and wall quenching to the total hydrocarbon emissions are obtained as:

$y_{\mathrm{f}, \text { out }}^{\text {cr }}=\frac{m_{\mathrm{f}, \text { out }}^{\text {cr }}}{m_{\mathrm{f}, \text { out }}}$

$y_{\mathrm{f}, \text { out }}^{\mathrm{sc}}=\frac{m_{\mathrm{f}, \text { out }}^{\mathrm{sc}}}{m_{\mathrm{f}, \text { out }}}$

$y_{\mathrm{f}, \text { out }}^{\mathrm{qu}}=1-y_{\mathrm{f}, \text { out }}^{\mathrm{cr}}-y_{\mathrm{f}, \text { out }}^{\mathrm{sc}}$.

Here, $y_{\mathrm{f}, \mathrm{qut}}^{\mathrm{qu}}$ is the relative contribution to the total hydrocarbon emissions from wall quenching. As seen from the calculation of $y_{\mathrm{f}, \text { out }}^{\mathrm{qu}}$, it is assumed in the model that unburned hydrocarbon emissions which are not due to crevices or short-circuiting are from wall quenching.

Possible post-oxidation of unburned fuel remaining in the cylinder after the main combustion has ended is accounted for in the model based on the expression [37]:

$\frac{\mathrm{d}[\mathrm{HC}]}{\mathrm{d} t}=1 \times 10^{13} e^{\frac{-48400}{R T}}[\mathrm{HC}]^{0.7}\left[O_{2}\right]^{0.8}$.

It is assumed in the model that the fuel undergoing post-oxidation is present in the vicinity of the cylinder wall, since it is fuel from the wall quench layer and fuel coming out of the crevices. Hence, the wall film temperature $T_{\mathrm{f}}=\frac{1}{2}\left(T_{\mathrm{g}}+T_{\mathrm{w}}\right)$ is used in the post-oxidation evaluation.

\section{Results and discussion}

\subsection{Validation}

The engine specifications are presented in Table 1 . The engine is applied as the propulsion system of a cargo vessel named Kvitbjrn from the Rolls Royce company. It is fueled with natural gas and utilizes two sets of control systems to
Table 1 Engine specification

\begin{tabular}{lll}
\hline Item & Unit & Amount \\
\hline Engine model & & B 35:40L9PG \\
Number of cylinders & - & 9 \\
Cylinder bore & $\mathrm{mm}$ & 350 \\
Cylinder stroke & $\mathrm{mm}$ & 400 \\
Connecting rod & $\mathrm{mm}$ & 810 \\
Rated speed & $\mathrm{rpm}$ & 750 \\
Rated power & $\mathrm{kW}$ & 3940 \\
Max Torque at rated speed & $\mathrm{Nm}$ & 50200 \\
Fuel type & - & Natural gas \\
\hline
\end{tabular}

adjust the stability of the engine: PID control system for settling the speed of the engine, and wastegate control system to regulate the air-fuel ratio. In former controller, the engine speed is defined to be fixed on $750 \mathrm{rpm}$. Proportional-integral coefficients in a closed loop govern the control process and restore the deviation by fuel injection period adaptation. In latter, observing any abnormality in the air-fuel ratio will be adjusted by wastegate valve using the same approach of PID controller. The valve diameter determines the amount of exhaust gases upstream of the turbine inlet, and the boost pressure provides the required air flow subsequently.

The architecture of the engine modeling is shown in Fig. 3. This structure provides modeling of the turbocharger system, intercooler, intake manifold, intake and exhaust valves, combustion chambers, and exhaust manifold. An imposed torque is implemented on the engine through the crankshaft and large mass inertia, and the output data are exported and stored schematic tank. These data are, in fact, the required input of the Type $\mathrm{E}$ and Type T models, as shown in Fig. 1.

The combustion coefficients are tuned based on the measured data, and Fig. 4 demonstrates the comparison of the normalized output of the engine modeling and measurement data with a satisfactory agreement in various loads. Figure $4 \mathrm{a}$, $\mathrm{b}$ shows for normalized brake-specific fuel consumption and unburned hydrocarbon, respectively. The normalizing factor for BSFC and UHC has gauged data at $100 \%$ load. The other data are measured at $85 \%, 75 \%, 50 \%$, and $25 \%$, all at a rated speed of $750 \mathrm{rpm}$.

To monitor a natural gas engine's response to dynamic load and the greatness of this variation on methane slip, a harmonic load has been imposed. Every individual case has taken a specific pattern of the load amplitude alternation $(5,10,15$, or $20 \%$ total deviation from the base load), with a constant frequency domain of $0.181 / \mathrm{s}$, adapted from [38]. Figure 5 draws a schematic structure of the loading with 0,10 , and $20 \%$ deviation (For instance, $20 \%$ deviation means $10 \%$ overload and $10 \%$ under load). The horizontal axis of this figure shows time (second) versus torque on the 


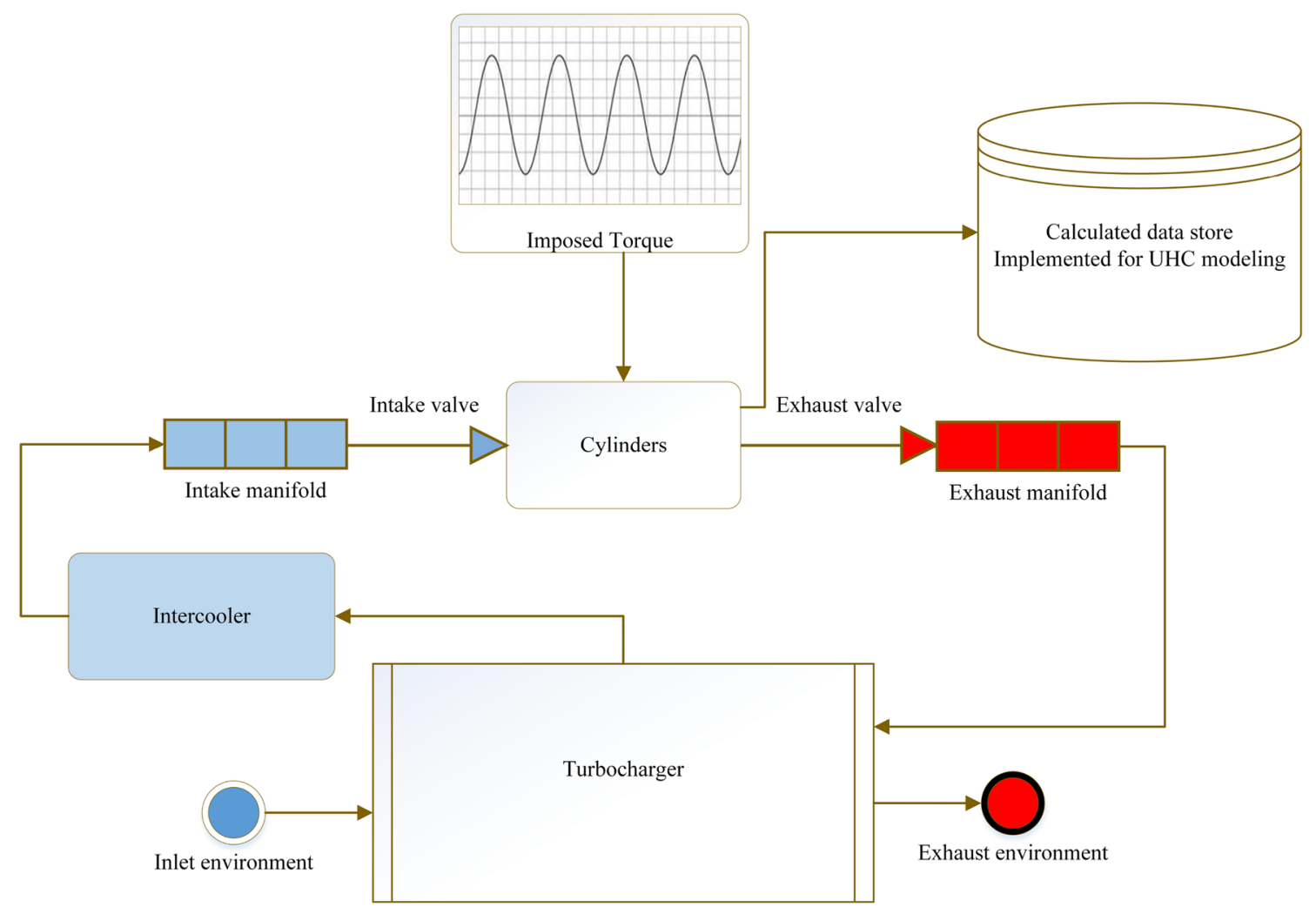

Fig. 3 Engine modeling flowchart

vertical axis. Due to numerical errors of the simulation and for the sake of reaching a stable condition, the modeling of harmonic load was commenced after $60 \mathrm{~s}$ of constant load and then proceeded until almost $149 \mathrm{~s}$ after start, equals to 16 full-wave cycles. This quantity of cycles ensures the independence of the results from a sudden change in the initial load transition.

\subsection{Unburned hydrocarbon modeling: Type E}

Figure 6 illustrates the results of implementing a harmonic sea wave load on the UHC volume from the Type E modeling. The amount of UHC at the commencement of the harmonic load has been viewed as a normalizing factor, so clearly the quantity of UHC before and after the harmonic load corresponds to just 1 . As can be seen, there is a notable correlation between load shifting and transition of UHC. Figure 6a shows that with 5\% load change, UHC decreases first around 20\% during higher load and afterward increases almost $40 \%$ during lower load. The average throughout the transient condition presents an entirely $4 \%$ UHC addition, given by the red line. Figure $6 \mathrm{~b}-\mathrm{d}$ also displays that the average UHC alternation for 10,15 , and $20 \%$ load variation is $13 \%, 29 \%$ and $49 \%$, sequentially. These diagrams indicated that UHC may momentarily increase up to $300 \%$ when the load of the engine lessens in the time scale of sea waves in harsh condition, and may just after decrease due to increasing load, resulting in a more efficient combustion than at nominal rate. The reduction of UHC is around half of the level at the nominal load and speed set point, so overall UHC level in transient conditions rises almost 50\% under sinusoidal load in the severe case of $20 \%$ load change.

\subsection{Unburned hydrocarbon modeling: Type T}

Performing simulation with the Type T model, it is possible to classify the unburned fuel emissions as resulting from crevice, gas exchange, and quenched mass fraction. Since the Type $\mathrm{T}$ model is an independent single cylinder model which is not included in the applied commercial software, verifying the pressure trace of this model is needed. This verification is done by comparing a normalized pressure trace in rated load and speed. Figure 7 documents that both models are giving the same results during all four phases of compression, combustion, expansion, and gas exchange. In addition, the relative difference of the amount of UHC of these models in the nominal load is almost equivalent and the disparity is less than $3 \%$, which is an acceptable difference. 


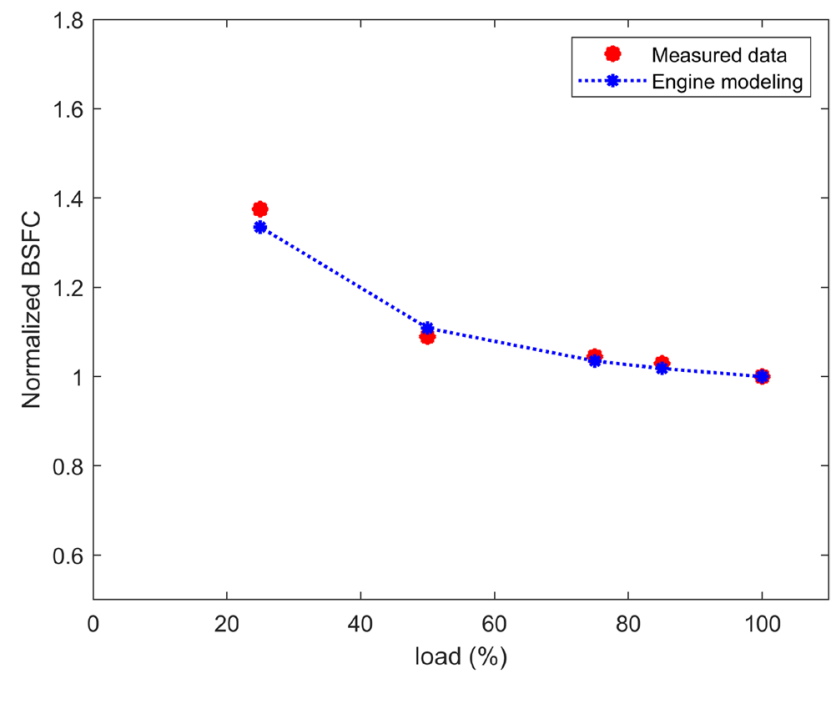

a Normalized BSFC

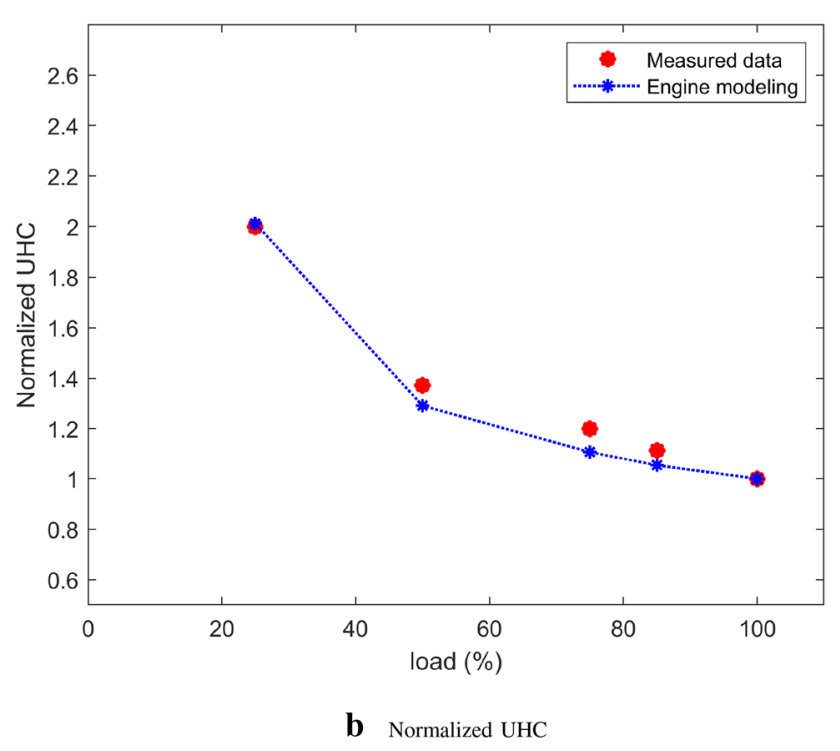

Fig. 4 Simulated and measured BSFC and UHC versus load at rated speed

To save the computation time, the Type T model is only applied during the wave load period, and not during the prior constant load period.

The results gained from the preliminary analysis of the Type T model are given in Fig. 8, and the investigation of the outputs reports $12 \%, 37 \%, 72 \%$, and $114 \%$ more UHC emitted from the engine when the loads vary $5,10,15$, and $20 \%$, respectively. The UHC level predicted in nominal load is equivalent to the output of Type $\mathrm{E}$ and has been used as a normalizing coefficient. In 5\% load oscillation, the maximum amount of UHC at lower load is $160 \%$, and at the higher load, it is $80 \%$ of that in nominal load, which means a $20 \%$ reduction. The time average level is totally

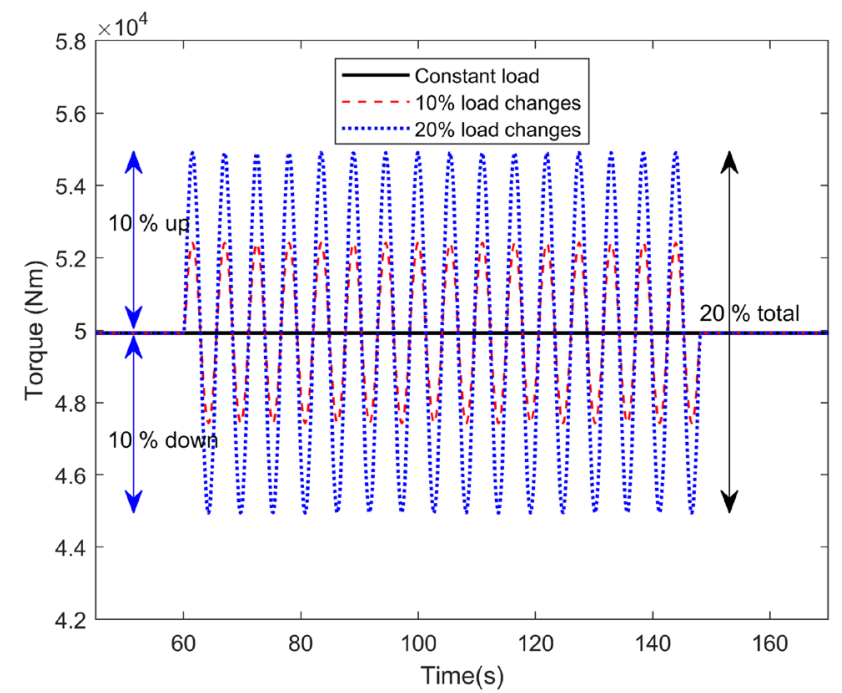

Fig. 5 Imposed dynamic load

$12 \%$ for under this load shift. With $20 \%$ load variation, $500 \%$ increase and $45 \%$ drop in UHC level are observed.

Comparing the variation predicted by the two models of UHC in Fig. 9 represents a considerable gap between these two models, especially in the higher percentage of the load curve. First reason shows itself up by taking Figs. 6 and 8 into consideration. The UHC amount in Fig. 8 reaches a minimum in higher load, and will not decrease any longer, despite the prediction at the Type E model, where the UHC level even reached $30 \%$ of the nominal UHC level at $20 \%$ load variation. Moreover, the highest amount of UHC predicted by the Type E model is hardly higher than $300 \%$, while with the Type T model, it goes up to $500 \%$. These differences of UHC formation demonstrate the importance of the post-oxidation process in the combustion chamber and the methodology of computing the mass amount and fraction of unburned fuel. It must be highlighted here that postoxidation calculation in the Type T model is a function of the average temperature of the wall and the hot gases, while the temperature used in the Type E model for post-oxidation is the burned gas temperature.

Fractional results in Fig. 10a-c from the Type T model are showing that up to $75 \%$ of UHC stems from crevice volume, maximum 3\% from gas exchange, and around $25 \%$ of unburned fuel originates from quenched flame at the nominal load and speed. Therefore, the gas-exchange UHC has the least influence on the UHC level amount, and this is reasonable, because the engine valve timing is redesigned for a natural gas engine application with a very short overlap. In the first few seconds, when the load increases, due to imposing a load shift, crevice is the only source of UHC and the reaction ends around 1, while the fraction of UHC by quenched flame decreases to $0 \%$ at 


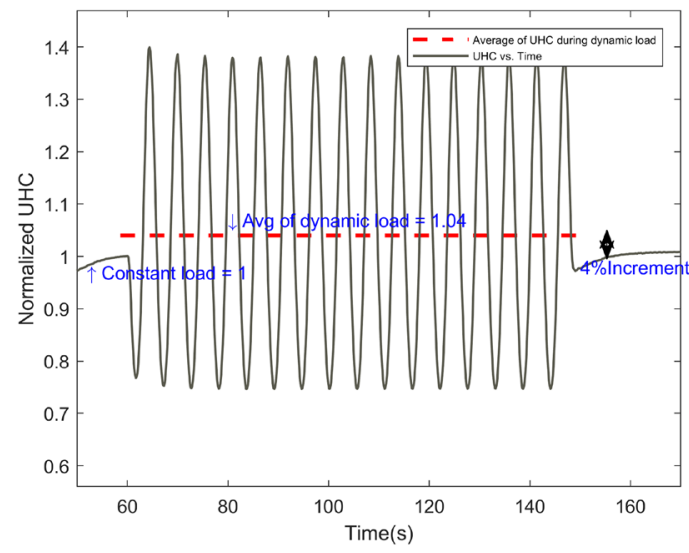

a $5 \%$ load variation

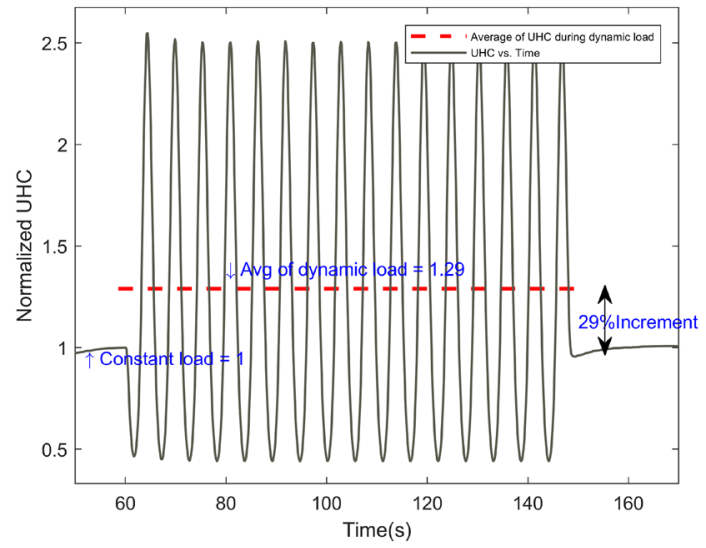

C $15 \%$ load variation

Fig. 6 Unburned hydrocarbon variation (modeling Type E)

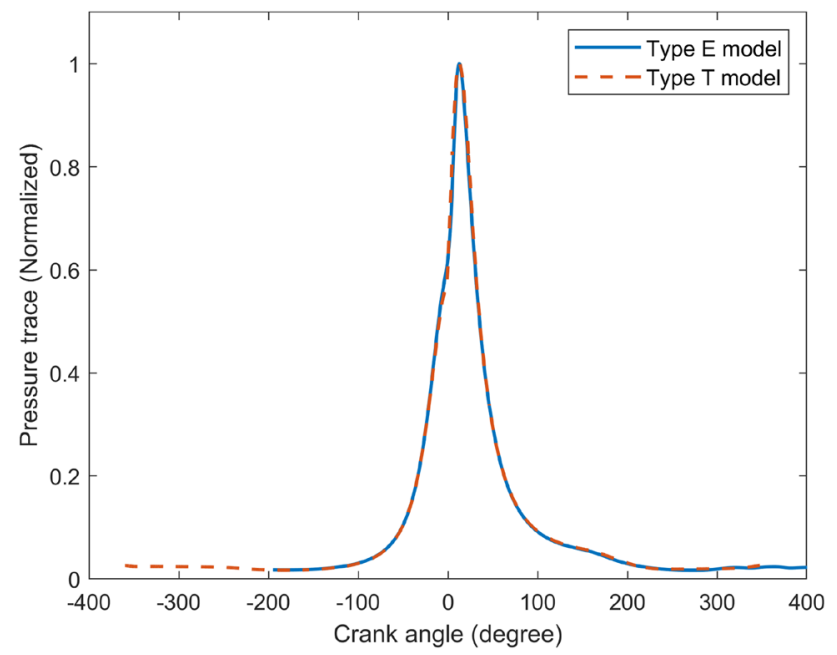

Fig. 7 Comparison of normalized pressure traces

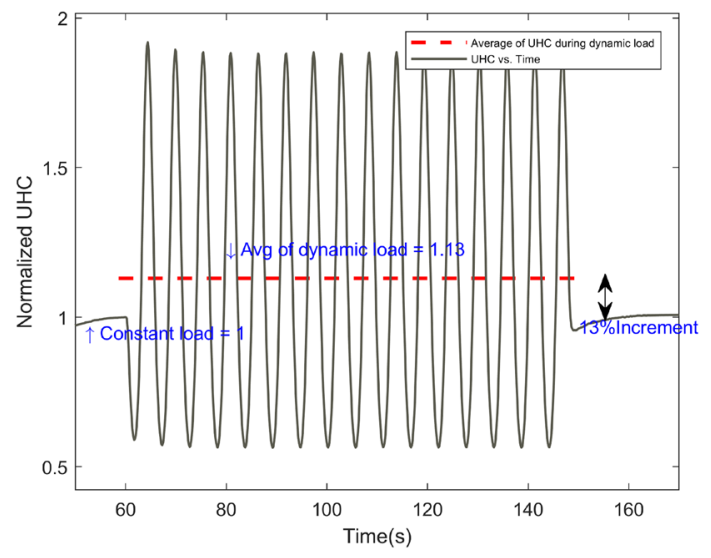

b $10 \%$ load variation

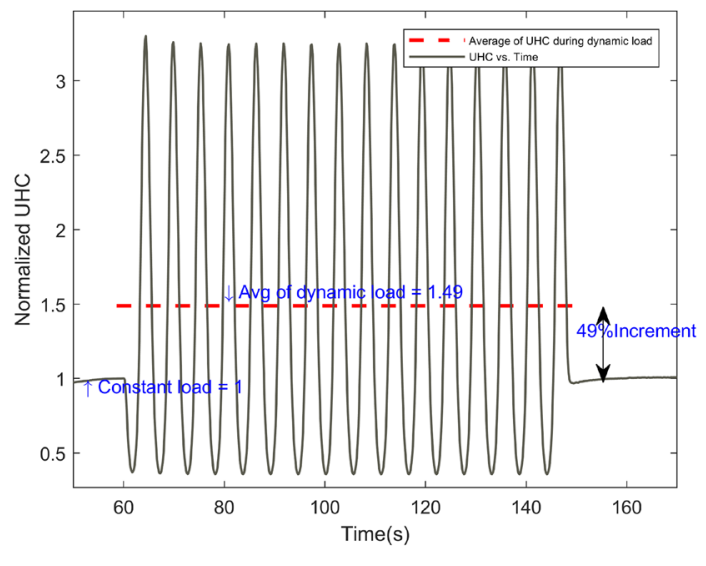

d $20 \%$ load variation

$20 \%$ load change. This proposes that the flame due to the flame speed and flame quality burns all of the fuel in the main chamber. This addresses the thought that the Type T model predicts a more reasonable output of UHC in the higher load than the Type E model, since as long as there is a crevice volume in the combustion chamber, there is a minimum UHC level as an output of the engine regardless of the load.

The mean lines in Fig. 10a likewise confirm that the UHC fraction due to the crevice volume changes a little, and in contrast, the UHC fraction due to quenched flame, Fig. 10c, changes more significantly when load oscillation increases. Taking Fig. 10b into account, UHC fraction due to the gas-exchange changes almost $15 \%$. However, this variation is a function of variation of the total UHC, and not due to the gas exchange itself, as shown in Fig. 11. It is instantly visible in the figure that quenched flame is nearly the only effective participant of UHC variation in transient marine conditions, as UHC mass due to crevice volume swings slightly around a persistent quantity. 


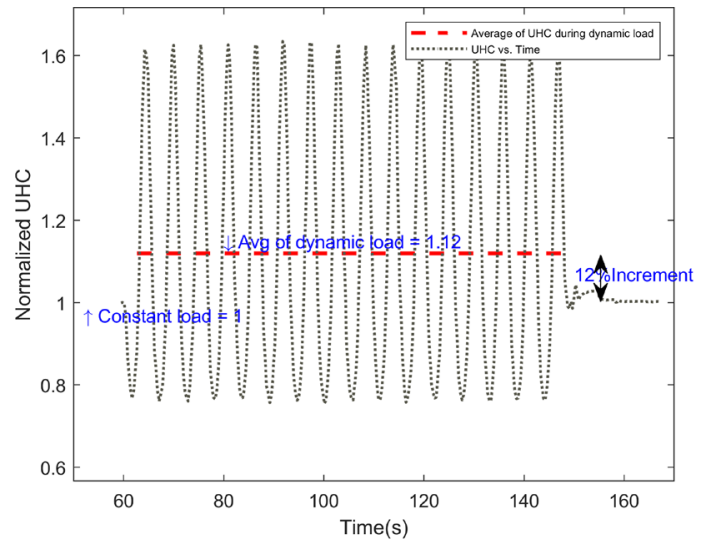

a $5 \%$ load variation

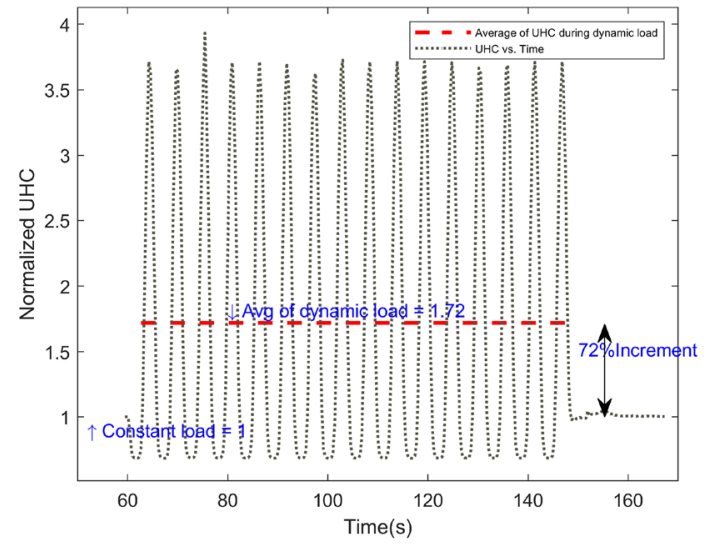

C $15 \%$ load variation

Fig. 8 Unburned hydrocarbon variation (modeling Type T)

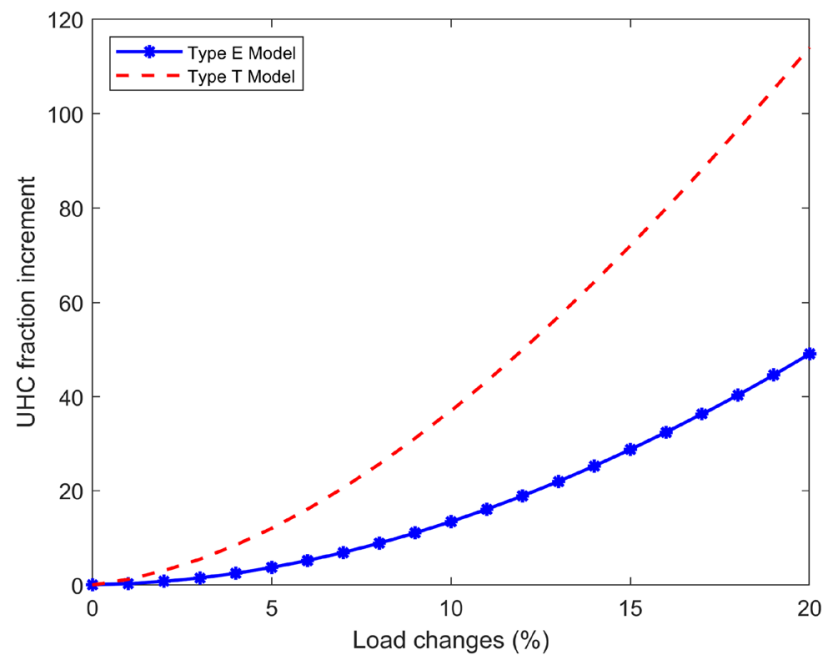

Fig. 9 UHC variation predicted by the two models

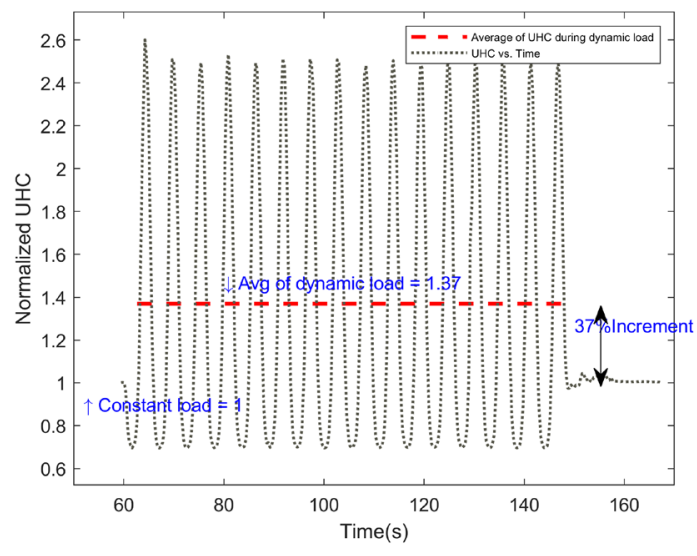

b $10 \%$ load variation

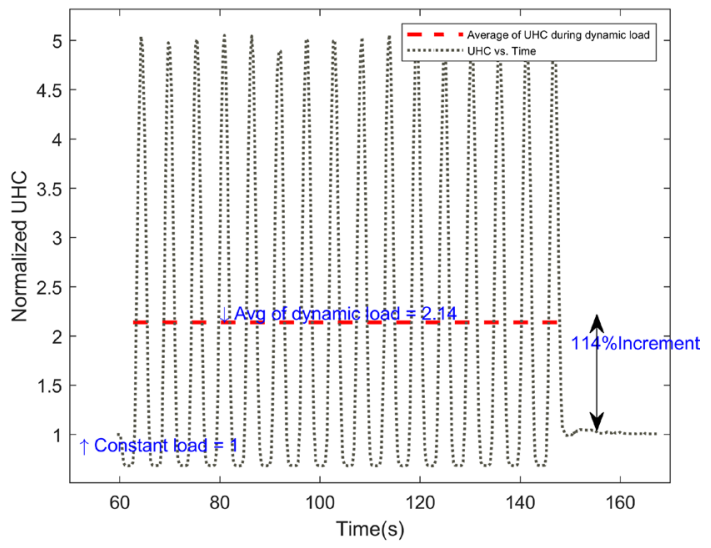

d $20 \%$ load variation

\subsection{Lean burn mixture sensitivity to dynamic load}

Comparing the UHC level with the rate of change of the air-fuel ratio shows that there is a direct correlation between these two parameters. Referring to Fig. 12, it is instantly visible that there are similarities between the variation of lambda during dynamic load period and the imposed variation of torque, as shown in Fig. 5. This indicates a need to understand the various perceptions of the air and fuel system first among all the existing port systems. Primary inspection revealed that load fluctuation ups and downs the required fuel to make up any speed variation deviated from nominal set point. This alternation of fuel flow asks for an equal change of the air flow, and since any command to the controller system to adjust the proper air is going to be done at the end of the exhaust manifold, even with the fastest PID response, there still exists some delay due to the dynamic of the system. Such time lag of the air system drives the engine to work at non-constant lambda.

To figure out how the air-fuel ratio itself influences the amount of UHC, lambda with certain values of 1.73, 1.78, 

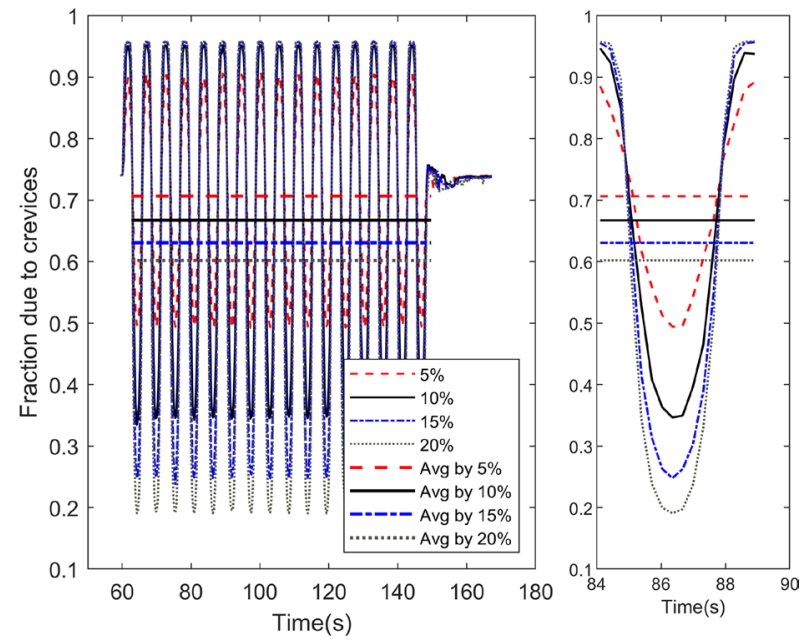

a Fraction of total UHC due to crevice
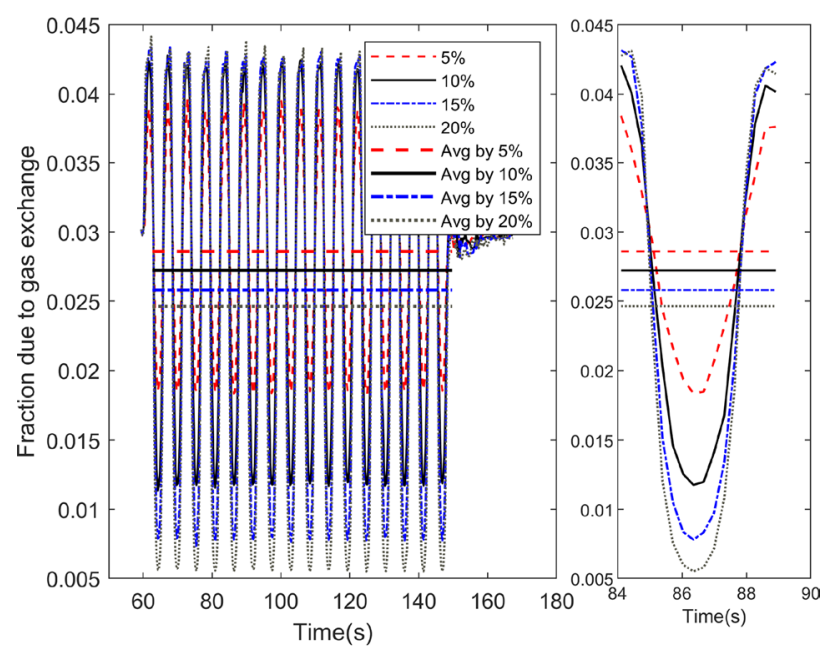

b Fraction of total UHC due to gas exchange

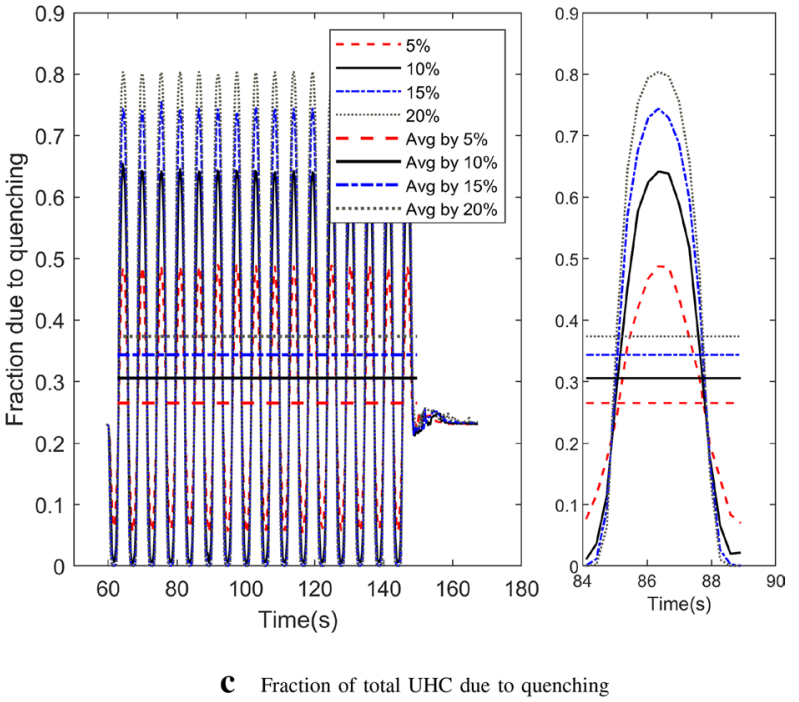

Fig. 10 UHC fraction distribution

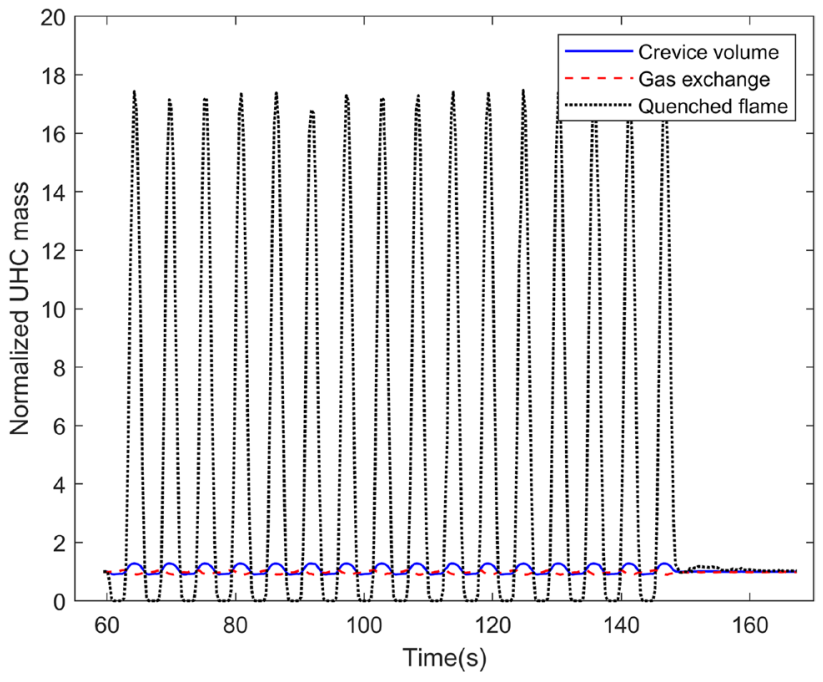

Fig. 11 Normalized mass of UHC sources with 20\% load variation

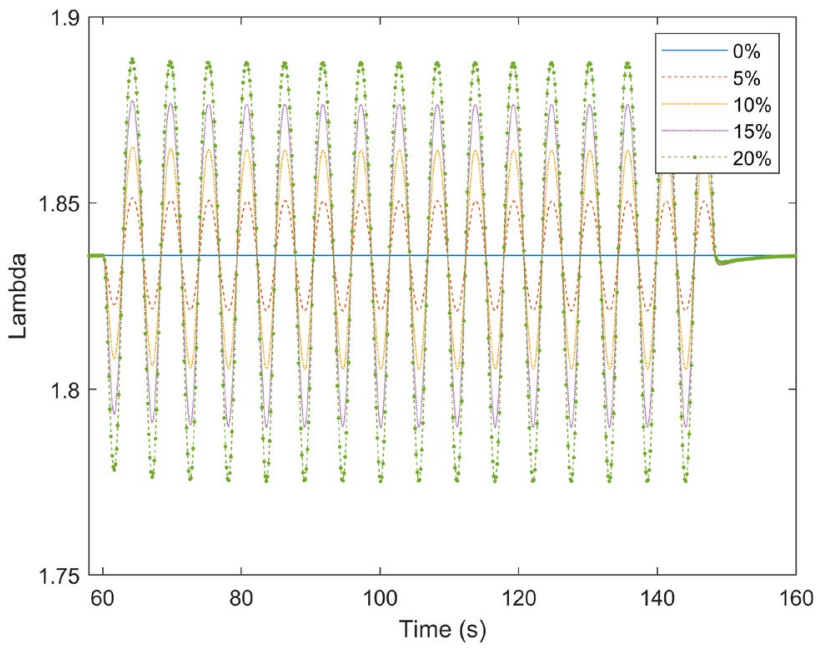

Fig. 12 Air-fuel ratio variation during dynamic load

1.83 , and 1.88 has been considered. Lambda equal to 1.83 is our base value of the study, and the target air-fuel ratio corresponding to these lambda values would be 29, 30, 31 (base value) and 32 . The findings of the simulations are shown in Fig. 13 and presents similarities between the rate of increasing level of UHC and the trend which appeared in Fig. 9. Lambda boosting multiplies UHC amount in constant load shown by blue columns. This explains to a high extend the significance of providing a firm air-fuel ratio based on the optimal set point.

Furthermore, the results display a contrasting tendency of the UHC pattern in dynamic load, as well. With higher lambda, here 1.88, the engine will produce less UHC in dynamic load. A possible explanation for this fact is that our considered engine is designed on the basis of least UHC 


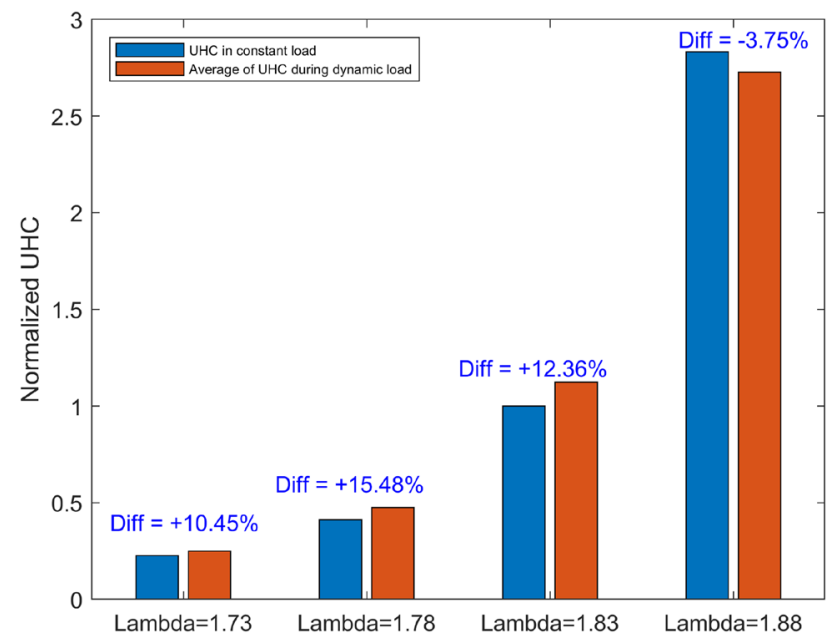

Fig. 13 Effect of air-fuel ratio on UHC level during static and dynamic load

in steady state; therefore, UHC will hardly reduce further in dynamic load, while it may increase quickly. Thus, expecting an increment of UHC during dynamic load is imminent. On the other hand, higher lambda produces higher UHC and both rise and fall of UHC occurs normally for both of the lower and higher load. Therefore, the reduction of UHC in dynamic load can only happen in a very lean or very bad UHC-based designed engine.

\section{Conclusion}

The amount of UHC in lean burn gas engines has been examined by modeling all subsystems of a marine engine. Two models have been used in the analysis of UHC emissions, with one having the capability of splitting the sources of UHC up. The results show that in stable condition, depending on crevice volume and lambda, UHC formation could be a function of only crevice volume to a high extend. Conversely in transient condition, the time lag in controlling the air-fuel ratio contributes to leaner or richer mixture, and the resulting flame speed slowness and incomplete combustion in leaner mixture areas very close to the wall causes a major part of the fuel being unburned. It was indicated that during $20 \%$ of oscillation load, the UHC level may be two times higher compared to a constant load case.

Acknowledgements Open Access funding provided by NTNU Norwegian University of Science and Technology (incl St. Olavs Hospital Trondheim University Hospital).

Open Access This article is licensed under a Creative Commons Attribution 4.0 International License, which permits use, sharing, adaptation, distribution and reproduction in any medium or format, as long as you give appropriate credit to the original author(s) and the source, provide a link to the Creative Commons licence, and indicate if changes were made. The images or other third party material in this article are included in the article's Creative Commons licence, unless indicated otherwise in a credit line to the material. If material is not included in the article's Creative Commons licence and your intended use is not permitted by statutory regulation or exceeds the permitted use, you will need to obtain permission directly from the copyright holder. To view a copy of this licence, visit http://creativecommons.org/licenses/by/4.0/.

\section{References}

1. European emission standards. https://en.wikipedia.org/wiki/Europ ean_emission_standards

2. International Maritime Organization. http://www.imo.org/en/ Pages/Default.aspx

3. United States Environmental Protection Agency. All epa emission standards. https://www.epa.gov/emission-standards-refer ence-guide/all-epa-emission-standards (last updated: 2017)

4. Rogelj J, den Elzen M, Höhne N, Fransen T, Fekete H, Winkler H, Ro Schaeffer, Sha F, Riahi K, Meinshausen M (2016) Paris agreement climate proposals need a boost to keep warming well below $2^{\circ} \mathrm{C}$. Nature 534:631-639

5. Karthickeyan V (2019) Effect of combustion chamber bowl geometry modification on engine performance, combustion and emission characteristics of biodiesel fuelled diesel engine with its energy and exergy analysis. Energy. https://doi.org/10.1016/j. energy.2019.04.012

6. Ragadia Sadiq Y, Iyer RC (2019) Experimental investigations on the influence of compression ratio and piston crown geometry on the performance of biogas fuelled small spark ignition engine. Renew Energy 146:996-1009

7. Abu Bakar Semin R (2008) A technical review of compressed natural gas as an alternative fuel for internal combustion engines. Am J Eng Appl Sci 1:302-311

8. Ushakov S, Stenersen D, Einang PM (2019) Methane slip from gas fuelled ships: a comprehensive summary based on measurement data. J Mar Sci Technol 24:1308-1325

9. ANNEX 11: RESOLUTION MEPC.304(72). Initial IMO strategy on reduction of GHG emissions from ships (2018)

10. The Intergovernmental Panel on Climate Change. Global warming potential values, 2016. IPCC Fifth Assessment Report

11. Brynolf S, Fridell E, Andersson K (2014) Environmental assessment of marine fuels: liquefied natural gas, liquefied biogas, methanol and bio-methanol. J Clean Prod 74:86-95

12. Heywood JB (1988) Internal combustion engines fundamental. McGraw Hill, New York

13. Cheng WK, Hamrin D, Heywood JB, Hochgreb S, Min M, Norris M (1993) An overview of hydrocarbon emissions mechanisms in spark-ignition engines. SAE (932708) (1993)

14. Wentworth JT (1968) Piston and ring variables affect exhaust hydrocarbon emission. SAE 77(68109):402-416

15. de Zwart M, van Dijk G, Klimstra J (2012) Methane emissions from gas engines driving combined heat and power installations. J Integr Environ Sci 9:113-125

16. Huang Z, Pan K, Li J, Zhou L, Jiang D (1996) An investigation on simulation models and reduction methods of unburned hydrocarbon emissions sin spark ignition engines. Combust Sci Technol. https://doi.org/10.1080/00102209608935525

17. Dyer TM (1985) On the source of unburned hydrocarbon emission from lean burn engines. VDI Ber 578:17-36

18. Lee S, Tong K, Quay BD, Zello JV, Santavicca DA (2000) Effects of swirl and tumble on mixture preparation during cold start of a gasoline direct-injection engine. SAE 109:1783-1796 
19. Cedrone KD (2013) Control strategy for hydrocarbon emissions in turbocharged direct injection spark ignition engines during coldstart. PhD thesis, Massachusetts Institute of Technology

20. Yu S, Min K (2002) Effects of the oil and liquid fuel film on hydrocarbon emissions in spark ignition engines. In: Proceedings of the Institution of Mechanical Engineers

21. Schramm J, Sorenson SC (1990) A model for hydrocarbon emission from SI engine. SAE (902169)

22. Abdel Rahman AA (1998) On the emissions from internal-combustion engines: a review. Int J Energy Res 22:483-513

23. Kalghatgi GT (1995) Combustion chamber deposits in sparkignition engines: a literature review. SAE (952443)

24. Haidar HA, Heywood JB (1997) Combustion chamber deposit effects on hydrocarbon emissions from a spark-ignition engine. SAE (972887)

25. Stpień Z (2014) Intake valve and combustion chamber deposits formation - the engine and fuel related factors that impacts their growth. Nafta-Gaz 4:236-242

26. Meernik PR, Alkidas AC (1993) Impact of exhaust valve leakage on engine-out hydrocarbons. SAE (932752)

27. Landsberg GB, Heywood JB, Cheng WK (2001) Contribution of liquid fuel to hydrocarbon emissions in spark ignition engines. SAE (2001-01-3587)

28. Robison JA, Brehob WM (1967) The influence of improved mixture quality on engine exhaust emissions and performance. J Air Pollut Control Assoc 17:446-453
29. Kato K, Igarash, K, Masuda M, Otsubo K, Yasuda A, Takeda K, Sato T (1999) Development of engine for natural gas vehicle. SAE (01-0574-1999)

30. Cho HM, He B-Q (2007) Spark ignition natural gas engines-a review. Energy Convers Manag 48:608-618

31. Tilagone R, Venturi S (2020) Development of natural gas demonstrator based on an urban vehicle with a down-sized turbocharged engine. Oil Gas Sci Technol 59:581-591

32. Kato T, Saeki K, Nishideb H, Yamada T (2001) Development of cng fueled engine with lean burn for small size commercial van. Soc Autom Eng Jpn (JSAE) 22:365-368

33. Williams FA (1985) Combustion theory, 2nd edn. Addison Wesley, Boston

34. Lavoie GA (1978) Correlations of combustion data for SI engine calculation-laminar flame speed, quench distance and global reaction rates. SAE (780229)

35. Gamma Technologies (2019) In-cylinder HC model

36. Schramm J (2019) Methane emission control. IEA Advanced Motor Fuels TCP-Annex 51 report

37. Westbrook CK, Dryer FL (1981) Simplified reaction mechanisms for the oxidation of hydrocarbon fuels in flames. Combust Sci Technol 27(1-2):31-43

38. Taskar B, Yum KK, Steen S, Pedersen E (2016) The effect of waves on engine-propeller dynamics and propulsion performance of ships. Ocean Eng 122:262-277 